$\Phi=\Phi$

\title{
Constraints that registered nurses in Namibia are faced with when utilising the nursing process in local-level Primary health care practice
}

\author{
Hermine Iita $^{1 *}$, Scholastika Iipinge ${ }^{2}$, Agnes $\operatorname{Van}_{\text {Dyk }}{ }^{3}$ \\ ${ }^{1}$ Lecturer School of Public Health, University of Namibia, Oshakati Campus \\ ${ }^{2}$ Professor and Dean of Nursing School, Welwitchia University, Windhoek: Namibia \\ ${ }^{3}$ Professor and Director of Nursing School. International University of Management, Windhoek: Namibia \\ *Corresponding authorE-mail: hiita@unam.na
}

\begin{abstract}
The purpose of this study was twofold. Firstly to explore and describe the utilization of the Nursing Process by registered nurses in local level Primary health care practice in Namibia with regard to Primary health care delivery during their daily practices and secondly, to develop strategies that would support registered nurses in executing their role and function in this regard. These were prompted by the implementation of a Primary health care approach to health care delivery in the country. The objectives of the study were:

- To Explore and describe the way in which registered nurses in clinics, health care centres and outreach posts in the health districts use the nursing process as regards PHC delivery;

- $\quad$ To determine how supervisors perceive the utilisation of the nursing process by registered nurses with regard to PHC;

- To identify the constraints that registered nurses are faced with when utilising the nursing process with regard to the delivery of PHC;

- To develop a conceptual framework on which to base the formulation of relevant strategies,

- To incorporate the findings of this study into the development of strategies to support registered nurses in their utilisation of the nursing process with regard to the delivery of PHC;

- To validate the appropriateness of these strategies.

A multi- phase, quantitative, exploratory, descriptive and contextual design was selected to provide a picture of how registered nurses fulfill their role and function concerning Primary health care (PHC) during their daily practices.

The population consisted of two groups. The first group consisted of 239 registered nurses working in Clinics, health Centres and in Outreach Programmes. The second group consisted of 39 registered nurses supervisors, who supervised the registered nurses in these facilities. A survey was used to gather the data through self-report (questionnaire). Two questionnaires were developed, one for registered nurses and the other for immediate supervisors. Quantitative, descriptive analysis was used to summarize and organize data using tables and figures as well as t-test and analysis of variance (ANOVA), where applicable. Five main areas where registered nurses needed support in execution of their roles and functions were revealed from the results. The areas were: Water and sanitation and other environmental health issues; health education and communication including outreach activities; Nutrition and food supply; Community diagnosis and care and Management support or administrative functions in Primary health Care, including research and education of health workers including fellow registered nurses.

This paper discusses the constraints that registered nurses in Namibia face when they use the nursing process in local Primary health care facilities.
\end{abstract}

Keywords: Constraints, Challenges; Local-Level Primary Health Care; Nursing Process; Primary Health Care; Registered Nurses.

\section{Introduction}

This paper is extracted from the authors study titled "Strategies to support the utilization of the nursing process by registered nurses in local-level Primary health care practice in Namibia.'The concept of primary health care (PHC) evolved in the 1940s and 1950s when the governments of several countries were urged by the World Health Organization (WHO) to rationalise their highly technical approaches to health care delivery and to broaden their coverage by providing basic services (WHO, 2009).
With the independence of Namibia in 1990, the Government of the Republic of Namibia adopted a health care system that places the focus on PHC, as a strategy to provide health care to all $\mathrm{Na}$ mibians in order to make health services easily accessible and available to all communities in Namibia, at a cost that the country and the communities could afford and with the emphasis on community-based health care. (Government of the Republic of Namibia: MOHSS 1992). In addition, health workers including registered nurses were re-oriented as regard the implementation of this approach (Iipinge, 2000). Accordingly, The University of Namibia revised the nursing education curriculum to prepare registered 
nurses to be ready to apply the PHC approach as adopted by the Government of Namibia (University of Namibia, 1995).

It is expected that registered nurses in Primary health care utilise the nursing process when they execute their daily fuctions. However, it is not clear whether registered nurses utilise the nursing process effectively in the provision of PHC, as adopted by the government, as a new and better strategy to render health care services in the country after independence in 1992.

This question was raised because health care statistics do not always reflect whether PHC is being executed satisfactorily. Research findings reveal insufficient health communication with clients in health care facilities (Iiyambo, 2005; GRN MOHSS 2006; Neshuku, 2005), while an increased prevalence of HIV/AIDS and tuberculosis and a lack of a healthy lifestyle are being observed in society.

It is as a result of these problems that the researchers in this study explored and described the extent to which registered nurses utilise the nursing process with regard to the delivery of PHC during their daily practice and, subsequently, developed strategies that would support registered nurses in their utilisation of the nursing process when executing their roles and functions in this regard.

This study was conducted in terms of both the framework of the model of nursing process, as well as the elements of PHC as applied to the role and functions of registered nurses and their supervisors in the PHC facility practice setting.

\section{Aim and objectives of the study}

The purpose of this study is twofold: firstly, to explore and describe the extent to which professional nurses use the nursing process in the delivery of PHC in their daily practice and, secondly, to develop strategies that would support registered nurses in their utilisation of the nursing process when executing their roles and functions in this regard.

The research objectives were as follow:

- To explore and describe the way in which registered nurses in clinics, health care centres and outreach posts in the health districts use the nursing process in PHC delivery.

- To determine how supervisors perceive the utilisation of the nursing process by registered nurses in PHC.

- To identify the constraints that registered nurses are faced with when utilising the nursing process in the delivery of PHC.

- To develop a conceptual framework on which to base the formulation of relevant strategies.

- To incorporate the findings of this study into the development of strategies to support registered nurses in their utilisation of the nursing process in PHC delivery.

- To validate the effectiveness of these strategies.

\section{Study design and methods}

The study was conducted in four phases namely as follow: Phase1: Needs assessment quantitative survey; Phase 2: Conceptualisation of findings from phase 1; Phase 3: Development of strategies to support the roles and functions of the registered nurse in local level PHC and Phase 4: Validation of these strategies.

This article describes objective 3 namely, to identify the constraints that registered nurses are faced with when utilising the nursing process in the delivery of PHC.

Only Primary health care role functions that were rated by more than $20 \%$ of the responses as below average.

\section{Design}

A quantitative research approach using a survey design with selfreport questionnaire was used.

\section{Methods}

The data that were gathered were on the application of PHC role functions during practice by registered nurses. This study was conducted in state clinics, health centres and outreach posts in health districts in all the health regions of Namibia.

The population comprised two groups. The first group consisted of 236 registered nurses working in clinics, health centres and outreach posts. The second group comprised 39 registered nurse supervisors, who supervised the registered nurses in these facilities. As a result of the restricted number of participants (registered nurses), the population and the sample were the same for this study and there was no sample selection.

The comments of the nursing service managers were scrutinised and used to inform the questionnaire. Two questionnaires were developed, one for registered nurses and the other for supervisors. The content of these two questionnaires was the same.

The questionnaires consisted of both open- and closed-ended questions and contained the following sections:

Section A consisted of biographical information -respondent's age, duration of service as a registered nurse, gender, work area, nursing qualification, duration of service at the current health facility, health district and health region.

Sections B to $\mathrm{G}$ consisted of items concerning the implementation of the PHC role functions within the study framework of the nursing process.

Section B dealt with assessment; section C diagnosis; section D planning; section $\mathrm{E}$ implementation; section $\mathrm{F}$ evaluation and section $\mathrm{G}$ recordkeeping.

This questionnaire was designed in such a way as to yield information on the entire targeted role functions that a registered nurse in local-level PHC in Namibia is expected to fulfil. Validity, reliability and pretesting

Validity and reliability was ensured by: submitting the instrument to the study supervisors and also by means of reviews by PHC experts. The supervisors agreed that the items that appeared were representative of the purpose of the study; content validity was assured by making sure that the questionnaire adequately covered the topic under study, namely, the utilisation of the nursing process in local-level PHC practice by registered nurses in their daily practice; In this study, the questionnaires were pretested to ascertain that the wording of the questions was not ambiguous. The questionnaires were also distributed to the senior nurse managers at the MOHSS in Namibia for review as recommended in literature (De Vos, Strydom, Fouche \& Delport, 2011; Jooste, 2009).

The questionnaires were either posted or delivered by hand to the participants, and then returned by post or collected by the principal researcher. The respondents - supervisors and registered nurses - were requested to complete the questionnaires. One supervisor could fill in more than one questionnaire if she/he supervised more than one registered nurse. Table 1 below summarises the statistics on questionnaires sent out and returned.

Table 1: Statistics of the Questionnaires Sent Out and Returned

\begin{tabular}{llll}
\hline & Sent out & Returned & Percentage \\
\hline Registered nurses & 236 & 164 & 69.4 \\
Supervisors & 236 & 144 & 61.0 \\
Total & 472 & 308 & 65.2 \\
\hline
\end{tabular}

Quantitative data analysis was done and involved the coding, categorising, ordering and systematic organising of the data in order to provide meaningful results (Levine \& Stephan, 2010). Descriptive analysis techniques were used to summarise and organise the data, using tables and figures to present the summarised findings. In addition, a t-test and analysis of variance (ANOVA) were performed on the data, where applicable (Ott \& Longnecker, 2010).

The descriptive data arising from the items on the questionnaires, where the registered nurses and their supervisors rated the fulfilment of the various PHC role functions by registered nurses, were analysed in order to determine the level at which each item had been rated. The mean score for each item were determined and this served as a yardstick for classifying specific items as well done, required moderate action or required urgent action. All the findings were presented in a comparison format in terms of which 
the ratings by the registered nurses were compared to the ratings by the supervisors. Student's t-test and ANOVA were also performed on specific variables to determine significant differences and their related variables.

After the data analysis had been completed, the researcher identified those functions which had been well done and for which the performance needed to be sustained, the functions which had required moderate actions and the functions that had required urgent actions. An item was classified as needed urgent action if rated by more than $20 \%$ of the responses as below average.
Three patterns were expected, namely, performance to be sustained (to sustain performance: $90 \%$ and more rated at average and higher); performance in terms of which moderate action is required (moderate action required: $80-89 \%$ rated as average and higher) and performance in terms of which urgent action is required (urgent action necessary: $>20 \%$ rated below average). These patterns are represented in figure 1 .

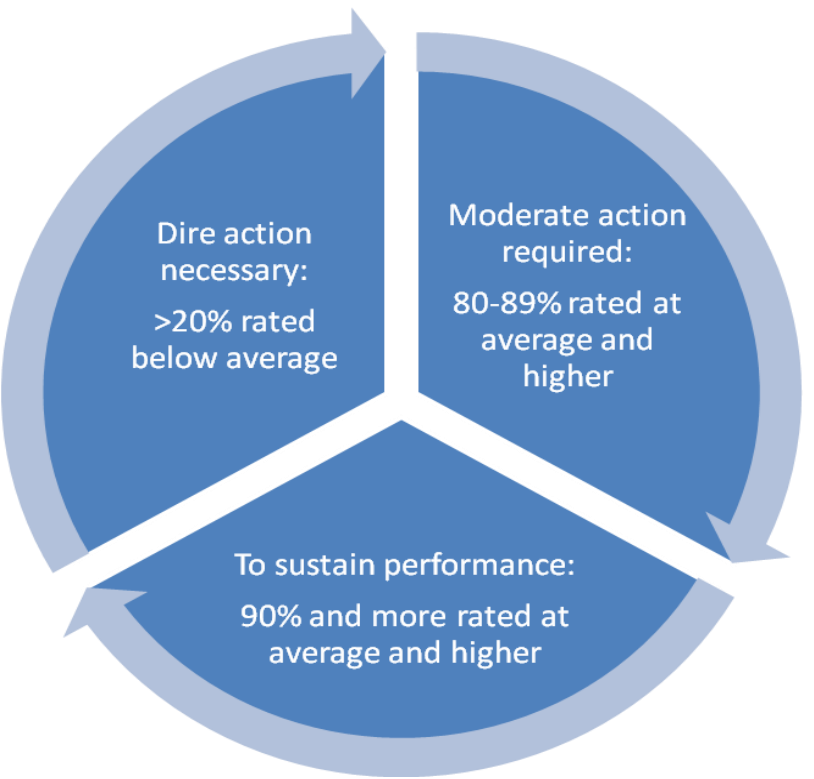

Fig. 1: Categorisation of Role Functions Based on the Rating of Their Fulfilment by the Participants.

With data analysis, a summary of the findings is presented in accordance with these patterns, namely, performance to be sustained, moderate action required and urgent action necessary.

The reader is advised to refer back to this section should the need arises.

Ethical measures were observed as follow: Written permission to conduct this study was granted by the MOHSS in Namibia before the data collection in phase 1 of the study commenced. Participants were fully informed regarding what the study entails. Confidentiality in this study was ensured because; the raw data were not shared in any way that may have jeopardised the safety of the participants. Participants in this study were told that they could refuse to participate in the study or could withdraw from the study at any time without any fear of coercion, thus voluntarism was ensured.

The anonymity of all the participants in this study was ensured in this way that the data from the field were not in any way linked to the individual respondent, while only data that was necessary for the project were collected. On completion of the study a copy of the complete study report was given to the Ministry of Health and the University of Namibia.

The participants in this study were not, in any way, exposed to either physical tests or treatment (Ervin, 2002).

\section{Findings}

The results of this study show that registered nurses in local-level, PHC practice in Namibia fulfil most of the roles and functions expected of them. However, they do face some challenges that make it difficult for them to execute some of their roles and functions in this regard. The following is a detailed description of challenges as identified in this study.

\section{Challenges identified}

The challenges identified fall into the following groups of PHC elements: water and sanitation and related environmental health issues; nutrition and food supply; health education and communication; community diagnosis and care; and management support or administration, including research. Table 2 presents a summary of challenges identified across elements of Primary health care and based on the steps of the nursing process.

\subsection{Challenges relating to water and sanitation and oth- er environmental health issues (environmental hygiene)}

The study results indicate that registered nurses do not adequately assess issues regarding environmental hygiene, such as the safety of drinking water, waste disposal, environmental health hazards and the housing conditions of clients in the catchment area. Some of the respondents did not have sufficient time to discuss these issues with the patients/clients while, in some instances, there was no contact between registered nurses in local health facilities and community health workers. The registered nurses claimed that, as a result of a lack of transport and the heavy workload at the health facilities, they did not find time to do assessment related to environmental health in the catchment areas. In addition, some of the respondents were of the opinion such environmental health assessment in the catchment area is the function of the health inspectors.

When these results are examined in relation to the other functions that have to do with the assessment of health and disease conditions, as well as the personal services provided to patients, the data suggest that more effort is needed in the assessment of the home environmentof the clients.

The data also suggest that it appeared as if the overlapping that exists between the role functions of the registered nurse in PHC and those of the health inspector, who also has a stake in community care, was not clear to every registered nurse as some of the 
registered nurses indicated that the said officials should be taking care of all issues related to the safety of drinking water, housing, and other aspects of environmental sanitation in the area.

Table 2: Primary Health Care Functions that Were Categorized as Needed Urgent Action in the Context of the Elements of Primary Health Care

\begin{tabular}{|c|c|c|}
\hline $\begin{array}{l}\text { Theme/Elements of } \\
\text { Primary health care }\end{array}$ & Role function area & $\begin{array}{l}\text { Phase of the } \\
\text { nursing process }\end{array}$ \\
\hline \multirow{5}{*}{$\begin{array}{l}\text { Health education and } \\
\text { communication }\end{array}$} & $\begin{array}{l}\text { Developmental status } \\
\text { of school children }\end{array}$ & assessment \\
\hline & $\begin{array}{l}\text { Need for home care } \\
\text { (assess) }\end{array}$ & Assessment \\
\hline & Outreach & Planning \\
\hline & Plan training sessions & Planning \\
\hline & Provide home care & Implementation \\
\hline \multirow[t]{2}{*}{ Nutrition and food supply } & $\begin{array}{l}\text { Food hygiene assess- } \\
\text { ment }\end{array}$ & Assessment \\
\hline & $\begin{array}{l}\text { Safety of drinking } \\
\text { water (environmental } \\
\text { sanitation) }\end{array}$ & Assessment \\
\hline \multirow{3}{*}{$\begin{array}{l}\text { Water and sanitation (envi- } \\
\text { ronmental hygiene) }\end{array}$} & $\begin{array}{l}\text { Waste disposal (envi- } \\
\text { ronmental sanitation) }\end{array}$ & Assessment \\
\hline & $\begin{array}{l}\text { Environmental health } \\
\text { hazards (environmen- } \\
\text { tal sanitation) }\end{array}$ & Assessment \\
\hline & $\begin{array}{l}\text { Housing (environmen- } \\
\text { tal sanitation) }\end{array}$ & Assessment \\
\hline $\begin{array}{l}\text { Community diagno- } \\
\text { sis/Community activities }\end{array}$ & $\begin{array}{l}\text { Social problems in } \\
\text { families and commu- } \\
\text { nities }\end{array}$ & Assessment \\
\hline \multirow{6}{*}{$\begin{array}{l}\text { Management and support } \\
\text { or administrative function }\end{array}$} & $\begin{array}{l}\text { Planning programmes } \\
\text { to manage illness }\end{array}$ & Planning \\
\hline & Plan budget & Planning \\
\hline & $\begin{array}{l}\text { Proposals for projects } \\
\text { (plan) }\end{array}$ & Planning \\
\hline & Implement budget & Implementation \\
\hline & $\begin{array}{l}\text { Training of health } \\
\text { workers and commu- } \\
\text { nity members }\end{array}$ & Implementation \\
\hline & Carry out research & Implementation \\
\hline
\end{tabular}

\subsection{Challenges regarding nutrition and food supply}

The research findings regarding nutrition and food supply showed that registered nurses do not adequately assess food hygiene, with some of the respondents indicating that their heavy workloads meant that they did not have enough time to do this or that this function was the responsibility of the health inspector. The data also suggest that the registered nurses were more concerned about the way in which the patients/clients were fed than they were about the quality of food hygiene in the catchment area. However, the literature suggests that registered nurses have a duty to ensure that their patients in the catchment area consume nutritious, wellbalanced and hygienic foodstuffs (Johnson, 2007; WHO, 1987; Whitney, De Bruyne, Pinna, \& Rolfes, 2007; Gibney, LanhamNew, Cassidy, \&Vorster, 2009).

\subsection{Challenges regarding health education and commu- nication}

The study results indicate that there was inadequate participation in activities related to the motivation and education of the community on the part of registered nurses. The registered nurses did not conduct adequate assessments of the developmental status of school children; they did not sufficiently assess the needs for home care; they did not sufficiently plan the education sessions of patients; they did not adequately conduct the training/education of fellow health workers; they did not adequately plan for all types of outreach services and there was inadequate provision of home care.
Outreach services are concerned with increasing access to PHC services in the community. Many of the respondents indicated that they did not feel that this function was adequately carried out. The MOHSS has a system in place in terms of which there is a team which is responsible for the outreach services in each health district (GRN MOHSS, 1992). This may, in fact, be one of the reasons why the study results indicated that the implementation rate of this activity was low. However, for those registered nurses who served in the mobile/outreach team, the results indicated that they had fulfilled the outreach functions well.

The issue of staff shortages was mentioned as a contributing factor as regards the nurses in the clinics and health centres not finding an opportunity to conduct outreach visits owing to high patient turnover at the health facilities. However, some of the supervisors expressed doubts about these claims.

\subsection{Challenges regarding the identification of social problems in families and communities}

According to the study results, the assessment of social problems in families and communities in the catchment area was inadequately carried out. This may suggest that the social life of families may deteriorate without the provision of proper support.

Table 3 contains the data described in the above sections. The problem areas are the once in which more than $20 \%$ of the responses rated the specific item as below average.

Shikongo (2008) made a similar finding in her study on "Assessing how registered nurses apply the sociology of development in their practice".

Despite the fact that a lack of transport was pointed out as the main reason why these roles and functions as regards the identification of social problems in families and communities were not adequately fulfilled, some of the supervisors claimed that there was also a degree of lack of commitment on the part of some registered nurses to strengthen their roles and functions in this regard, as there were situations in which these may have been fulfilled even when no transportation had been organised.

\subsection{Challenges regarding management and support or administrative functions}

These challenges include the following: insufficient involvement of registered nurses in the role functions related to management and support or administration; registered nurses do not plan sufficiently for programmes managing illness; registered nurses do not take sufficient part in budget planning; registered nurses do not take sufficient part in the planning of project proposals; registered nurses do not take adequate part in the implementation of the budget; registered nurses do not take sufficient part in the training and education of health workers and registered nurses do not take sufficient part in research activities. These data is contained in table 4 . In addition, a shortage of staff and a lack of transport were also cited as challenges in this regard.

Inadequate participation in programme planning on the part of registered nurses.

Proper planning for programme activities facilitates the correct and prompt implementation of these programmes and this, in turn, ensures the realisation of the programme objectives (Johnson, 2007; Stanhope \& Lancaster, 2008; Jooste, 2010). The results of this study indicate that the registered nurses felt that they did not contribute to programme planning.

Registered nurses do not take sufficient part in budget planning.

The registered nurses indicated that they did not participate sufficiently in budget planning, while the supervisors claimed there was also, to a certain extent, a lack of/inadequate awareness in some instances.

The possible danger if employees including registered nurses are not included in planning is, they may feel that they are not part of the planning process and there may be a lack of support for programme implementation, as well as a lack of care in handling resources. However, the study results indicate that the registered 
nurses in Namibia are reasonably efficient in ensuring that the materials and equipment are used for the correct purpose.

Registered nurses do not take sufficient part in the planning of project proposals.

As in the case of budgeting, the planning of proposals is also position linked and not every registered nurse takes part in the devel- opment of project proposals. In fact, some of the registered nurses indicated they were not even aware of those functions happening in the health facilities, while others maintained that it is the responsibility of the supervisors to take care of such functions.

Table 3: Statistical Results of the Assessment Step: Percentages (\%), Means and Frequencies (N)

\begin{tabular}{|c|c|c|c|c|c|c|c|c|c|}
\hline & \multicolumn{4}{|c|}{$\begin{array}{l}\text { PERCENTAGES } \\
\text { below average aver }\end{array}$} & \multicolumn{2}{|c|}{ above average } & \multicolumn{3}{|c|}{ MEAN } \\
\hline & $\mathrm{R} / \mathrm{n}$ & Sup & $\mathrm{R} / \mathrm{n}$ & Sup & $\mathrm{R} / \mathrm{n}$ & Sup & $\mathrm{R} / \mathrm{n}$ & Sup & Total \\
\hline Occurrence of health problems in your catchment area. & $\begin{array}{l}13.5 \\
(\mathrm{~N}=22)\end{array}$ & $\begin{array}{l}12.7 \\
(\mathrm{~N}=18)\end{array}$ & $\begin{array}{l}31.9 \\
(\mathrm{~N}=52)\end{array}$ & $\begin{array}{l}33.1 \\
(\mathrm{~N}=47)\end{array}$ & $\begin{array}{l}54.6 \\
(\mathrm{~N}=89)\end{array}$ & $\begin{array}{l}54.2 \\
(\mathrm{~N}=77)\end{array}$ & 3.65 & 3.54 & 3.60 \\
\hline Occurrence of important diseases in the community & $\begin{array}{l}16.2 \\
(\mathrm{~N}=26)\end{array}$ & $\begin{array}{l}9.2 \\
(\mathrm{~N}=13)\end{array}$ & $\begin{array}{l}30.4 \\
(\mathrm{~N}=49)\end{array}$ & $\begin{array}{l}35.5 \\
(\mathrm{~N}=50)\end{array}$ & $\begin{array}{l}53.4 \\
(\mathrm{~N}=86)\end{array}$ & $\begin{array}{l}55.3 \\
(\mathrm{~N}=78)\end{array}$ & 3.6 & 3.6 & 3.60 \\
\hline Safety of drinking water for clients in catchment area & $\begin{array}{l}24.0 \\
(\mathrm{~N}=31)\end{array}$ & $\begin{array}{l}21.9 \\
(\mathrm{~N}=31)\end{array}$ & $\begin{array}{l}24.8 \\
(\mathrm{~N}=54)\end{array}$ & $\begin{array}{l}38.0 \\
(\mathrm{~N}=54)\end{array}$ & $\begin{array}{l}50.3 \\
(\mathrm{~N}=81)\end{array}$ & $\begin{array}{l}38.0 \\
(\mathrm{~N}=54)\end{array}$ & 3.29 & 3.28 & 3.31 \\
\hline Conditions under which waste is being disposed of in the area & $\begin{array}{l}29.8 \\
(\mathrm{~N}=41)\end{array}$ & $\begin{array}{l}28.7 \\
(\mathrm{~N}=41)\end{array}$ & $\begin{array}{l}41.5 \\
(\mathrm{~N}=65)\end{array}$ & $\begin{array}{l}39.2 \\
(\mathrm{~N}=56)\end{array}$ & $\begin{array}{l}28.5 \\
(\mathrm{~N}=45)\end{array}$ & $\begin{array}{l}30.1 \\
(\mathrm{~N}=43)\end{array}$ & 2.91 & 3.06 & 2.99 \\
\hline The extent of food hygiene in the area & $\begin{array}{l}24.5 \\
(\mathrm{~N}=40)\end{array}$ & $\begin{array}{l}25.2 \\
(\mathrm{~N}=36)\end{array}$ & $\begin{array}{l}32.5 \\
(\mathrm{~N}=53)\end{array}$ & $\begin{array}{l}40.6 \\
(\mathrm{~N}=58)\end{array}$ & $\begin{array}{l}42.9 \\
(\mathrm{~N}=70)\end{array}$ & $\begin{array}{l}32.2 \\
(\mathrm{~N}=46)\end{array}$ & 3.22 & 3.20 & 3.20 \\
\hline Nutritional status of clients & $\begin{array}{l}18.4 \\
(\mathrm{~N}=30)\end{array}$ & $\begin{array}{l}9.1 \\
(\mathrm{~N}=13)\end{array}$ & $\begin{array}{l}27.6 \\
(N=45)\end{array}$ & $\begin{array}{l}39.4 \\
(\mathrm{~N}=56)\end{array}$ & $\begin{array}{l}53.8 \\
(\mathrm{~N}=88)\end{array}$ & $\begin{array}{l}50.0 \\
(\mathrm{~N}=71)\end{array}$ & 3.58 & 3.60 & 3.59 \\
\hline $\begin{array}{l}\text { Environmental health hazards } \\
\text { (e.g. standing, dirty water, etc.) }\end{array}$ & $\begin{array}{l}34.0 \\
(\mathrm{~N}=55)\end{array}$ & $\begin{array}{l}29.2 \\
(\mathrm{~N}=42)\end{array}$ & $\begin{array}{l}24.7 \\
(\mathrm{~N}=40)\end{array}$ & $\begin{array}{l}34.0 \\
(\mathrm{~N}=49)\end{array}$ & $\begin{array}{l}41.3 \\
(\mathrm{~N}=67)\end{array}$ & $\begin{array}{l}34.7 \\
(\mathrm{~N}=50)\end{array}$ & 3.06 & 3.11 & 3.09 \\
\hline Need for housing \& shelter in your health area & $\begin{array}{l}37.4 \\
(\mathrm{~N}=59)\end{array}$ & $\begin{array}{l}35.7 \\
(\mathrm{~N}=51)\end{array}$ & $\begin{array}{l}22.8 \\
(\mathrm{~N}=36)\end{array}$ & $\begin{array}{l}28.0 \\
(\mathrm{~N}=40)\end{array}$ & $\begin{array}{l}39.9 \\
(\mathrm{~N}=63)\end{array}$ & $\begin{array}{l}34.3 \\
(\mathrm{~N}=49)\end{array}$ & 3.06 & 3.02 & 3.04 \\
\hline Do you take a complete history of all patients/client who you examine & $\begin{array}{l}6.7 \\
(\mathrm{~N}=11)\end{array}$ & $\begin{array}{l}6.3 \\
(\mathrm{~N}=9)\end{array}$ & $\begin{array}{l}19.5 \\
(\mathrm{~N}=32)\end{array}$ & $\begin{array}{l}22.2 \\
(\mathrm{~N}=32)\end{array}$ & $\begin{array}{l}73.7 \\
(\mathrm{~N}=121)\end{array}$ & $\begin{array}{l}70.8 \\
(\mathrm{~N}=102)\end{array}$ & 4.03 & 3.02 & 4.00 \\
\hline All observations pertaining to a patient (BP, pulse, respiration) & $\begin{array}{l}7.9 \\
(\mathrm{~N}=13)\end{array}$ & $\begin{array}{l}5.6 \\
(\mathrm{~N}=8)\end{array}$ & $\begin{array}{l}13.4 \\
(\mathrm{~N}=22)\end{array}$ & $\begin{array}{l}29.9 \\
N=43)\end{array}$ & $\begin{array}{l}78.7 \\
(\mathrm{~N}=129)\end{array}$ & $\begin{array}{l}64.6 \\
(N=93)\end{array}$ & 4.10 & 3.93 & 4.02 \\
\hline Health status of any patients who are diagnosed with any disease & $\begin{array}{l}7.3 \\
(\mathrm{~N}=12)\end{array}$ & $\begin{array}{l}7.7 \\
(\mathrm{~N}=11)\end{array}$ & $\begin{array}{l}20.1 \\
(\mathrm{~N}=33)\end{array}$ & $\begin{array}{l}30.6 \\
(N=44)\end{array}$ & $\begin{array}{l}72.5 \\
(\mathrm{~N}=119)\end{array}$ & $\begin{array}{l}61.1 \\
(\mathrm{~N}=88)\end{array}$ & 3.99 & 3.76 & 3.86 \\
\hline Check up of women six weeks after delivery (Post natal) & $\begin{array}{l}18.1 \\
(\mathrm{~N}=30)\end{array}$ & $\begin{array}{l}16.8 \\
(\mathrm{~N}=24)\end{array}$ & $\begin{array}{l}22.0 \\
(\mathrm{~N}=36)\end{array}$ & $\begin{array}{l}24.5 \\
(\mathrm{~N}=35)\end{array}$ & $\begin{array}{l}59.1 \\
(\mathrm{~N}=97)\end{array}$ & $\begin{array}{l}56.7 \\
(\mathrm{~N}=81)\end{array}$ & 3.66 & 3.74 & 3.64 \\
\hline Immunisation status of all infants and children under the age of 5 years & $\begin{array}{l}4.2 \\
(\mathrm{~N}=7)\end{array}$ & $\begin{array}{l}3.5 \\
(\mathrm{~N}=5)\end{array}$ & $\begin{array}{l}13.4 \\
(\mathrm{~N}=22)\end{array}$ & $\begin{array}{l}15.4 \\
(\mathrm{~N}=22)\end{array}$ & $\begin{array}{l}82.3 \\
(\mathrm{~N}=135)\end{array}$ & $\begin{array}{l}81.1 \\
(\mathrm{~N}=116)\end{array}$ & 4.34 & 4.32 & 4.33 \\
\hline Need for Vitamin A for children under 5 years & $\begin{array}{l}6.2 \\
(\mathrm{~N}=10)\end{array}$ & $\begin{array}{l}7.0 \\
(\mathrm{~N}=10)\end{array}$ & $\begin{array}{l}22.1 \\
(\mathrm{~N}=36)\end{array}$ & $\begin{array}{l}23.6 \\
(\mathrm{~N}=34)\end{array}$ & $\begin{array}{l}71.8 \\
(\mathrm{~N}=117)\end{array}$ & $\begin{array}{l}69.5 \\
(N=100)\end{array}$ & 4.11 & 4.03 & 4.07 \\
\hline Tetanus vaccination status of all women of child-bearing age (15-45) & $\begin{array}{l}12.9 \\
(\mathrm{~N}=21)\end{array}$ & $\begin{array}{l}16.0 \\
(N=23)\end{array}$ & $\begin{array}{l}20.2 \\
(\mathrm{~N}=33)\end{array}$ & $\begin{array}{l}25.7 \\
(\mathrm{~N}=37)\end{array}$ & $\begin{array}{l}66.9 \\
(\mathrm{~N}=109)\end{array}$ & $\begin{array}{l}58.3 \\
(\mathrm{~N}=84)\end{array}$ & 3.92 & 3.73 & 3.83 \\
\hline Health development status of school children & $\begin{array}{l}28.5 \\
(\mathrm{~N}=46)\end{array}$ & $\begin{array}{l}30.8 \\
(\mathrm{~N}=44)\end{array}$ & $\begin{array}{l}28.6 \\
(\mathrm{~N}=46)\end{array}$ & $\begin{array}{l}29.4 \\
(\mathrm{~N}=42)\end{array}$ & $\begin{array}{l}42.9 \\
(\mathrm{~N}=69)\end{array}$ & $\begin{array}{l}37.1 \\
(\mathrm{~N}=53)\end{array}$ & 3.16 & 3.14 & 3.15 \\
\hline Social problems in families and community & $\begin{array}{l}23.4 \\
(N=38)\end{array}$ & $\begin{array}{l}23.8 \\
(N=44)\end{array}$ & $\begin{array}{l}34.0 \\
(\mathrm{~N}=55)\end{array}$ & $\begin{array}{l}39.2 \\
(\mathrm{~N}=56)\end{array}$ & $\begin{array}{l}42.6 \\
(N=69)\end{array}$ & $\begin{array}{l}35.0 \\
(\mathrm{~N}=50)\end{array}$ & 3.25 & 3.24 & 3.24 \\
\hline Need for home care & $\begin{array}{l}26.9 \\
(\mathrm{~N}=43)\end{array}$ & $\begin{array}{l}21.1 \\
(\mathrm{~N}=30)\end{array}$ & $\begin{array}{l}21.3 \\
(\mathrm{~N}=54)\end{array}$ & $\begin{array}{l}32.4 \\
(\mathrm{~N}=46)\end{array}$ & $\begin{array}{l}51.9 \\
(\mathrm{~N}=83) \\
\end{array}$ & $\begin{array}{l}44.3 \\
(\mathrm{~N}=63) \\
\end{array}$ & 3.40 & 3.47 & 3.43 \\
\hline
\end{tabular}

Table 4: Descriptive Statistical Results of Roles and Functions that Require Planning: Percentages (\%), Means and Frequencies (N)

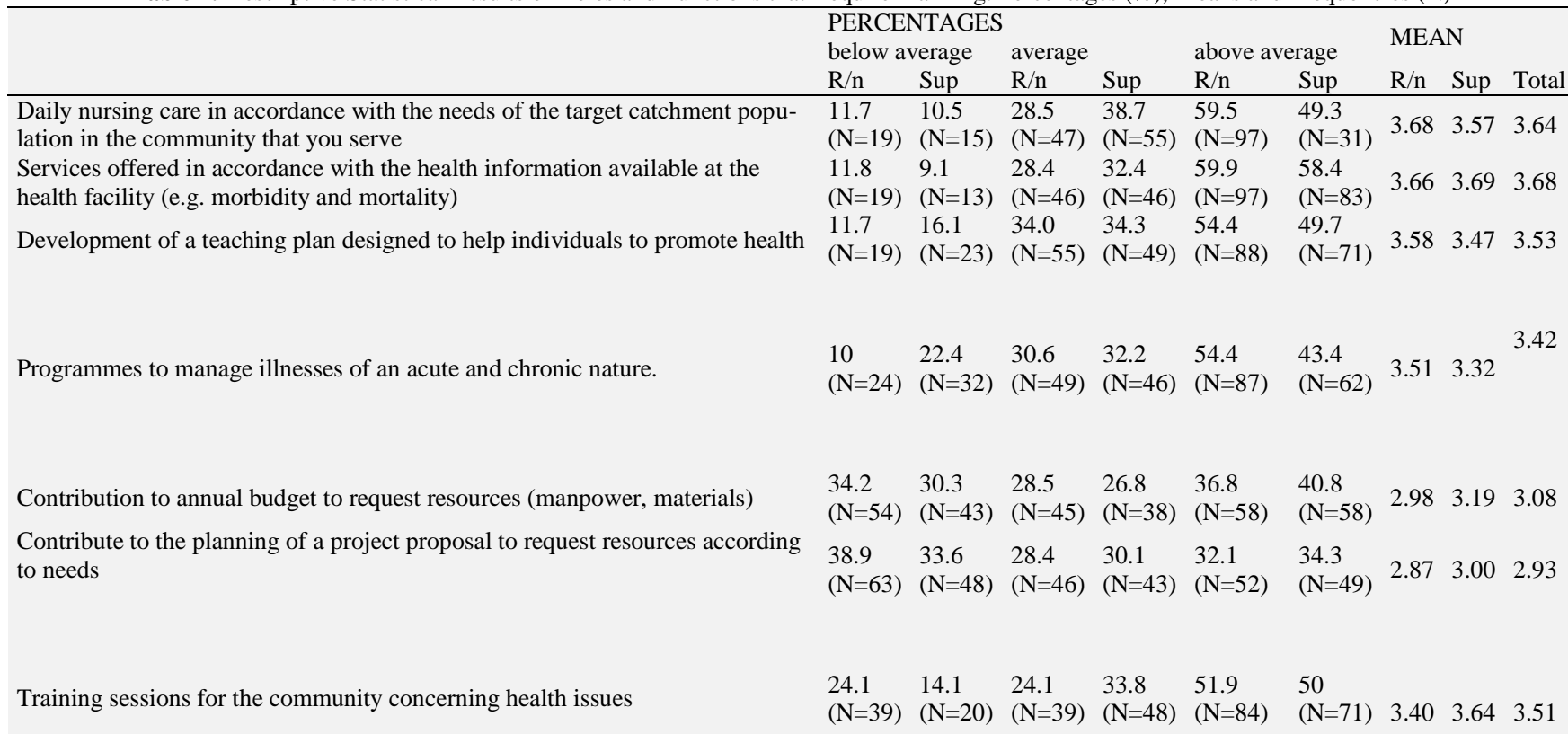


Training sessions for staff on relevant issues

For all health promotion activities (e.g. growth monitoring, home visiting, AIDS prevention, immunisation)

Nursing interventions for any health problem identified

Outreach services in the community

Registered nurses do not take sufficient part in the implementation of the budget plan.

Programme planning, budgeting and proposal writing are all activities that are position linked, while, in the MOHSS in Namibia, not all the activities relating to these services are visibly decentralised, a situation that may cause some health workers to feel uninvolved if proper communication at facility level is not ensured (GRN, 1992; Official National Primary Health Care /Community Based Health Care Guidelines).

Registered nurses do not adequately participate in the training and education of health workers.

The education of health workers is the best tool with which to update knowledge and skills, a condition that is required for enhanced practice (Mason-Whitehead \& Mason, 2008; Jooste 2010). However, the study results indicate that this function was not well done.

Registered nurses do not take sufficient part in research activities.

\begin{tabular}{|c|c|c|c|c|c|c|c|c|}
\hline 3.7 & $J=15)$ & $N=5$ & $\begin{array}{l}25.9 \\
(\mathrm{~N}=3\end{array}$ & 4 & 84) & 6 & 3.82 & 3.7 \\
\hline & 8 & (a) & ) & 1 & D) & 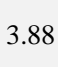 & 3.4 & \\
\hline & & & & & & .02 & 8 & \\
\hline 40) & $\begin{array}{l}21.7 \\
(\mathrm{~N}=31)\end{array}$ & $\begin{array}{l}17.4 \\
(\mathrm{~N}=28)\end{array}$ & $\begin{array}{l}7.5 \\
V=25)\end{array}$ & $\begin{array}{l}57.8 \\
(\mathrm{~N}=93\end{array}$ & $\begin{array}{l}8.1 \\
\mathrm{~N}=83)\end{array}$ & & 3.48 & \\
\hline
\end{tabular}

Research provides evidenced-based information to guide decision making and innovation. However, the study results indicate that registered nurses are not conducting research adequately. The reasons cited for not conducting research included the following: no time to do so as a result of heavy workload at the health facility, lack of knowledge, ignorance regarding when and where to do it and not involved. The implication is that if research is not conducted problems may go unnoticed, no solutions to problems will be found and/or no improvements will be effected. The supervisors remarked that there was an element of inadequate insight from the site of registered nurses as they do not seem to recognise the contribution they make to research at facility or community level by, for example, keeping accurate statistics/health information; analysing the disease trends reflected in the daily clinic records of patients; recording all cases seen; and reporting suspected outbreaks. The data regarding implementation of management and administrative aspects are contained in table 5.

Table 5: Implementation Descriptive Statistical Results: Percentages (\%), Means And Frequencies (N)

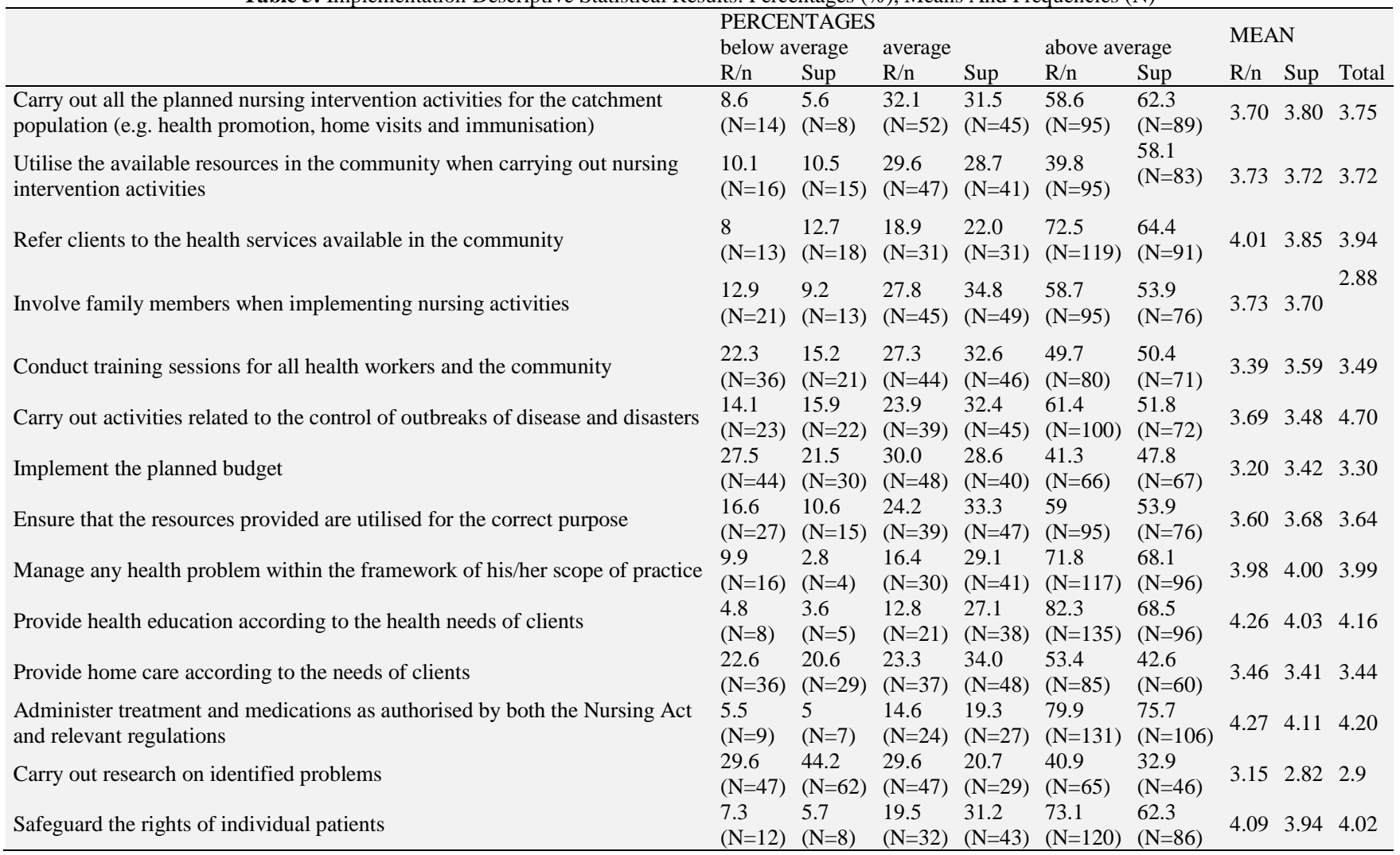

Insufficient resources (staff and materials) and facilities to ensure adequate fulfilment of primary health care nursing role functions The registered nurses and the supervisors cited inadequate staffing and a lack of transport as the main reasons why most PHC functions were not sufficiently implemented. They also indicated that heavy workloads at the health facilities in the presence of shortages of registered nurses made life more difficult at this level of PHC practice. Nevertheless, some of the supervisors also claimed that there was an element of inadequate commitment on the part of some of the registered nurses because there were instances in which the health facility was not always overcrowded and yet no health education was being given. Some of the supervisors also felt that some of the registered nurses needed support as regards prioritising duties.

The possible dangers associated with insufficient staffing, coupled with heavy workloads, include: the staff, in this case the registered nurses, being overworked and developing burnout syndrome; poor quality of services and, subsequently, de-motivation (Booyens, 1999; Morrison, 2008 ).

\section{Discussion of the findings}

The results of this study revealed the following challenges based on the elements of PHC practice and the use of the nursing process by registered nurses: 
Areas of concern in environmental health issues

- Insufficient assessment of safety of drinking water for patients/clients by registered nurses.

- Inadequate assessment of waste disposal in the catchment area by registered nurses.

- Inadequate assessment of environmental health hazards by registered nurses.

- Poor assessment of housing conditions for patients/clients in the catchment area by registered nurses.

Area of concern as regards nutrition and food supply

- Inadequate assessment of food hygiene in the catchment area by registered nurses.

Areas of concern pertaining to health information and motivating the community

- Inadequate assessment of developmental status of school children.

- Inadequate planning for patient's and health workers' education.

- Inadequate assessment of patients' needs for home care.

- Inadequate provision of home care by registered nurses.

Area of concern as regards outreach

- Inadequate planning for outreach services by registered nurses.

Area of concern as regards the identification of social problems in families and communities/community diagnosis and care

- Inadequate assessment of social problems of families and communities.

Area of concern as regards research

- Inadequate participation in research activities by registered nurses.

Areas of concern as regards managerial and administrative aspects of PHC

- Shortage of staff and heavy workload.

- Lack of resources: staff and transport.

- Financial management.

If the identified challenges are considered in relation to the steps of the nursing process, these challenges are in the areas of assessment and planning. The assessment of environmental health issues (sanitation), health education and health communication, including outreach services, food hygiene and the assessment of social problems in communities and families, were not adequately performed by all registered nurses. As regards planning, the functions related to programme and financial planning, planning for health education and health communication, including outreach services, were also not adequately performed. These findings may, thus, imply that diagnosis, implementation and evaluation may also be deficient in some areas because it is assessment and diagnosis that guides all the functions which are implemented in order to solve the problems which have been identified in PHC nursing (Ackley \& Ladwig, 2008; Clark, 2008; McGloin \& McLeod, 2010).

The factors that contributed to registered nurses not utilising the nursing process effectively in their daily PHC practice include: a shortage of registered nurses; not being involved in budgeting; not being provided with the transport necessary to carry out their functions; not being exposed to certain activities for lengthy periods of time, for example outreach; heavy workloads, including large numbers of patients/clients to manage; and not having enough time to visit communities as a result of the heavy workload at the clinics and health centres. This workload makes life extremely difficult for the nurses

These constraints were also identified by Neshuku (2005) and Iiyambo (2005). In the study of one district conducted by Neshuku (2005), regarding support for nursing staff in PHC, lack of transport was also one of the constraints identified. However, Neshuku also identified other managerial constraints, such as inadequate telephone communication and working space, as challenges that were contributing to the difficulties faced by registered nurses. The findings of this study, when compared to those of Neshuku (2005), may have implications for a possible improvement in the management of PHC services in Namibia, or alterna- tively could mean that the challenges faced by registered nurses in local-level PHC facilities differ from those faced at the hospital level of PHC delivery.

\section{Conclusions}

From the results that were analysed, it is clear that registered nurses in local-level, PHC practice in Namibia fulfil most of the roles and functions expected of them. However, they do face some challenges that make it difficult for them to execute some of their roles and functions in this regard. The challenges were categorised according to the five elements of PHC and management, namely, water and sanitation and related environmental health issues; nutrition and food supply; health education and communication; community diagnosis and care; and management support or administration, including research.

\section{Recommendations}

It was recommended that strategies be developed to support registered nurses when they use the nursing process in their daily practices in local Primary health care practice. The strategies will be addressed in a separate paper.

\section{Acknowledgements}

The researchers would like to express their appreciations to the following institutions and individuals: University of Namibia for the financial and technical support; The Ministry of Health and Social Services (MOHSS) in Namibia for granting permission for this study to be carried out as well as for technical support; All the registered nurses who work in the local Primary Health Care facilities in the thirteen regions for the information they provided which helped to make this study happen.

\section{References}

[1] Ackley, B. J., \& Ladwig, G. B. (2008). Nursing diagnosis handbook. New York, USA: Mosby Elsevier.

[2] Booyens, S. W. (1999). Dimensions of nursing management (2nd ed.). Cape Town: Juta.

[3] Clark, M. J. (2008). Community health nursing: Advocacy for population health $\left(5^{\text {th }}\right.$ ed.). USA: Prentice Hall.

[4] De Vos, A. S., Strydom, H., Fouche, C. B., \& Delport, C. S. L. (2011).Research at grass roots: For the social sciences and human service professions (4th ed.). Pretoria, South Africa: Van Schaik.

[5] Ervin, N. E. (2002). Advanced community health nursing practice. New Jersey, USA: Prentice Hall.

[6] Gibney, M. J., Lanham-New, S. A., Cassidy, A., \&Vorster, H. H (2009). Introduction to human nutrition:The Nutrition Society textbook series (2nd ed.). Oxford, UK: Wiley-Blackwell.

[7] Government of the Republic of Namibia (GRN).Ministry of Health and Social Services (MOHSS) (1992).The Official National Primary Health Care/Community Based Health Care Guidelines. Windhoek Namibia: Ministry of Health and Social Services.

[8] Government of the Republic of Namibia (GRN) Ministry of Health and Social Services (MOHSS). (24 March 2006). National Guidelines for the Management of Tuberculosis ( $2^{\text {nd }} \mathrm{ed}$.). Windhoek: Ministry of Health and Social Services.

[9] Government of the Republic of Namibia (GRN). Ministry of Health and Social Services (MOHSS) [Namibia]. (2006). Namibia Demographic and Health Survey. Windhoek, Namibia:(MOHSS)

[10] lipinge, S. N. (2000). Evaluation of the PHC/CGHC capacity building programme of the Ministry of Health and Social Services since 1992-1998. Windhoek, Namibia: University of Namibia.

[11] Iiyambo, L. (2005). Investigation information needs and accessibility of information of health workers in rural health center: A case study of Musty and Oshana regions. A project submitted in partial fulfilment for Bachelor of Arts Degree in Library Science and record management. Department of Information and Communication Studies, University of Namibia, University of Namibia Windhoek. 
[12] Johnson, B. L. (2007). Environmental policy and public health. London, UK: CRC Press.

[13] Jooste, K. (2009). Supervision in nursing practice: Professional nurses series. Pretoria, South Africa: Van Schaik.

[14] Jooste, K. (2010). The principles and practice of nursing and health care: Ethos and professional practice, management, staff development and research. Pretoria, South Africa: Van Schaik.

[15] Levine, D. M., \& Stephan, D. F. (2010). Even you can learn statistics. A guide for everyone who has ever been afraid of statistics (2nd ed.). New York, USA: Pearson Education.

[16] Mason-Whitehead, E., \& Mason, J. (2008).Study skills for nurses (2nd ed.). London, UK: Sage.

[17] McGloin, S., \& McLeod, A. (2010). Advanced practice in critical care: A case study approach. London, UK: Wiley-Blackwell.

[18] Morrison, J. (2008). The relationship between emotional intelligence and preferred conflict-handling styles. Journal of Nursing Management, 16, 974-983. http://dx.doi.org/10.1111/j.13652834.2008.00876.x.

[19] Neshuku, H. (2005). Support in the form of resources from MOHSS available to primary health care workers in Onandjokwe District in the North West Health Region, Namibia.Submitted in accordance with the requirements for the degree of Masters in Nursing Science at the University of Namibia. Department of Nursing Science. October 2005.W indhoek: University of Namibia.

[20] Ott, R., \& Longnecker, M. L. (2010). An introduction to statistical methods and data analysis. (6th ed.). New York: Books/Cole Cengage Learning.

[21] Shikongo, K. K. I. (2008). Strategies to facilitate application of sociology of development to nursing practice. Doctoral thesis submitted in partial fulfilment of the requirement for the degree of doctor of nursing science in the Faculty of Medical and Health Sciences at the University of Namibia.

[22] Stanhope, M., \& Lancaster, J. (2008). Public health nursing: Population-centered health care in the community (7th ed.). Canada: Mosby, Elsevier.

[23] Whitney, E., De Bruyne, L. K., Pinna, K., \& Rolfes, S. K. (2007). Nutrition for health and health care (3rd ed.). USA: Thomson.

[24] World Health Organization (WHO). (1987). the community health worker: Working guide. Guidelines for training. Guidelines for adaptation. Geneva, Switzerland: World Health Organization

[25] World Health Organization (WHO). (2009). WHO: Primary health care. Accessed from http://www.who.int/topics/primary health care/en/.on the 6/6/2009. 